\title{
Estudo De Caso: Linfoma Não-Hodgkin
}

- Foram descritos 18,1 milhões de casos novos de câncer em todo o mundo com 9,6 milhões de mortes em 2018. No Brasil, a estimativa para 2018 e 2019 é de 1,2 milhões de novos casos. É a segunda principal causa de morte em todo o mundo, já sendo a primeira causa de morte em 10\% dos municípios brasileiros, superando as doenças cardiovasculares;

- A doença pode se tornar a primeira causa de morte da população se nada for feito com o objetivo de prevenção da doença;

- Nos últimos 20 anos observou-se um aumento de 90\% na mortalidade por neoplasias, uma evolução três vezes mais rápida do que a mortalidade por doenças cardiovasculares nesse período (aumento de 36\%);

- A literatura aponta a genética como sendo responsável por 5 a 10\% das causas de cânceres, sendo 90 a $95 \%$ relacionadas a fatores ambientais, dos quais se destacam como principais fatores de risco evitáveis o baixo consumo de frutas e vegetais, a obesidade, a resistência à insulina, o tabagismo, o sedentarismo, e algumas infecções, como a infecção pelo vírus HPV;

- Do ponto de vista imunológico, a prevalência de uma resposta imune com o fenótipo de macrófago M1 caracteriza um perfil mais inflamatório e a cronicidade dessa resposta pode ser favorável para o desenvolvimento do câncer. Por outro lado, na prevalência do perfil de macrófagos do tipo M2, temos uma resposta menos inflamatória, e, portanto com perfil mais antitumoral;

- Estudos associam o perfil emocional com o sistema imunológico, podendo ter correlações com o desenvolvimento das doenças oncológicas. Estudos mostram que indivíduos mais resilientes (mais adaptados a lidar com os desafios), têm uma maior prevalência de macrófagos M2 e, portanto, poderiam ter menos risco para desenvolver câncer;

- Além disso, outros estudos mostram que indivíduos mais otimistas e com bons relacionamentos intrapessoal e interpessoal, tem menor produção de citocinas pró-inflamatórias, envolvidas com uma resposta imunológica mais favorável ao desenvolvimento das doenças oncológicas;

- Outro fator relacionado ao câncer pode estar associado à perda da capacidade imunológica em combater as células tumorais, uma vez que há escape das células cancerígenas do sistema imunológico;

- A microbiota intestinal tem papel de extrema importância em todas as etapas do câncer: na prevenção, na modulação dos efeitos adversos da terapia antineoplásica e na reposta ou não da imunoterapia dependendo do tipo de microbiota do indivíduo;

- Um dos objetivos no tratamento nutricional do paciente oncológico é melhorar a capacidade imunológica do indivíduo modulando a microbiota intestinal para que a mesma tenha maior prevalência de bactérias probióticas, bem como diversidade da mesma; 
- O butirato, um ácido graxo de cadeia curta oriundo de fibras solúveis como inulina, goma guar, amido resistente, betaglucana de leveduras, aumenta a diversidade da microbiota intestinal, tornando-a mais saudável. Ainda, atua inibindo a proliferação tumoral, uma vez que elevadas concentrações de butirato são entregues às células cancerosas e inibem a HDAC, o que aumenta a acetilação de histonas, resultando na paragem do ciclo celular, indução de apoptose e supressão da angiogênese, tornando as células cancerígenas mais visíveis para o sistema imunológico;

- Metanálise correlacionou a enteropatia associada ao glúten com elevado risco de linfoma não-Hodgkin, sendo importante a investigação da sensibilidade ao glúten nesses casos, para um tratamento nutricional adequado quanto à retirada ou não do glúten da dieta;

- Alta ingestão de alimentos lácteos está associada aos fatores que aumentam à susceptibilidade ao câncer pelo estímulo da via do mTOR, que poderia induzir o aumento da proliferação de células cancerígenas. Observase nos estudos que a ingestão de proteína animal aumenta significativamente os níveis de IGF-1, o que não é observado com a ingestão de proteína vegetal;

- Alta ingestão de frutas e verduras, entre 400 e $800 \mathrm{~g} /$ dia está relacionada com menor susceptibilidade ao câncer, devendo ser estimulado o consumo de alimentos vegetais naturais aos indivíduos que estão em tratamento do câncer e que também querem prevenir recidivas, bem como novos cânceres.

\section{Referências bibliográficas}

1. STRAUSBERG, R.L. Tumor microenvironments, the immune system and cancer survival. Genome Biol; 6(3): $211,2005$.

2. INTERNATIONAL AGENCY FOR RESEARCH ON CANCER. Global cancer observatory. World Health Organization; 2018. http://gco.iarc.fr/.

3. HAGERLING, C.; CASBON, A.J.; WERB, Z.B. Balancing the innate immune system in tumor development. Trends Cell Biol; 25(4): $214-220,2015$.

4. REED, R.G.; RAISON, C.L. Stress and the Immune System. In: HAGGERTY, H.G. Encyclopedia of Immunotoxicology; p. 97-126, 2016.

5. WORLD CANCER RESEARCH FUND. AMERICAN INSTITUTE FOR CANCER RESEARCH. Food, Nutrition, Physical Activity, and the Prevention of Cancer: a Global Perspective. Washington DC: AICR, 2018.

6. AUNE, D.; GIOVANNUCCI, E.; BOFFETTA, P. et al. Fruit and vegetable intake and the risk of cardiovascular disease, total cancer and all-cause mortality - a systematic review and dose-response meta-analysis of prospective studies. Int J Epidemiol; 46(3):1029-1056, 2017.

7. HOLMES, M.D.; POLLAK, M.N.; WILLETT, W.C. et al. Dietary correlates of plasma insulin-like growth factor I and insulin-like growth factor binding protein 3 concentrations. Cancer Epidemiol Biomarkers Prev; 1(9): 852-861, 2002.

8. DREWES, J.L.; HOUSSEAU, F.; SEARS, C.L. Sporadic colorectal cancer: microbial contributors to disease prevention, developmen and therapy. Br J Cancer.; 115(3): 273-280, 2016.

9. JUNYI, Y.; INÉS, M.; JENS, W. et al. In vitro characterization of the impact of selected dietary fibers on fecal microbiota composition and short chain fatty acid production. Molecular biology, genetics and biotechnology; 23: 74-81, 2013. 